\title{
A new dermoscopic finding in Ota nevus
}

\section{Selma El Kadiri, Hanane Bay Bay, Rhizlane Chaoui, Zakia Douhi, Sara Elloudi, Fatima Zahra Mernissi}

\author{
Department of Dermatology and Venereology, University Hospital Hassan II, Fez, Morocco
}

Corresponding author: Dr. Selma El Kadiri, E-mail: elkadiri-s@hotmail.com

Sir,

Nevus of Ota or nevus fusco-caeruleus ophthalmomaxillaris is a dermal melanocytic nevus is characterized clinically by blue gray patches and macules along the first and second branches of trigeminal nerve [1]. Here we report the case of a patient with new dermoscopic findings.

A 22-year-old female presented with asymptomatic pigmented lesions on the first dermatome of trigeminal nerve since the age of 10 years. Clinical examination revealed a bluish hyperpigmented patch involving forehead, periorbiteal area and temple (Fig. 1). No pigmentation was found in the sclera of homolateral eye ni Ito nevus was found. Dermoscopy showed blue-grayish structureless with iridescent reflections and white rosettes in many places (Figs. 2a and 2b). Hence, a diagnosis of nevus of Ota was formulated.

Nevus of Ota is a dermal melanocytic nevus presented clinically with blue to grey pigmentation along the branches of trigeminal nerve. It may affect the eye, nasal or oral mucosa, auditory external canal and tympanic membrane [1]. The risk is the development of glaucoma and more rarely malignant melanoma. In their series of 10 cases of Ota nevi, Elmas and al described gray structureless areas and scattered brown-gray dots as the most common dermoscopic finding [2]. Rosettes are defined as four white points arranged as a four leaf clover. They are a result of pathological involving the follicular and perifollicular area [3]. It has been recently reported in a bue nevus [4]. To best of our knowledge, this is the first case of Ota nevus with rosettes.

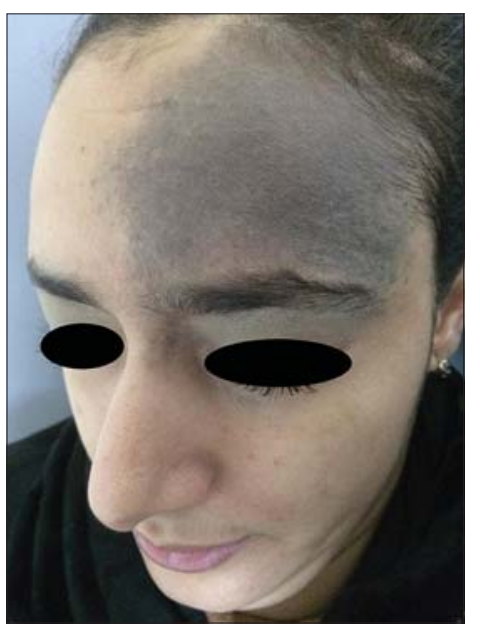

Figure 1: Blue nevus of the first branche of trigeminal nerve.

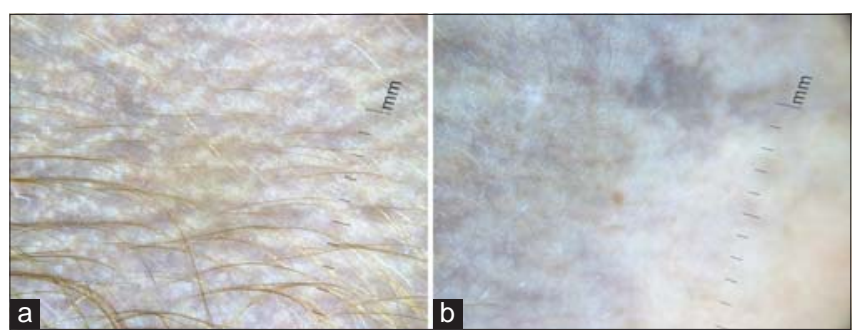

Figure 2: ( $a$ and b) Dermoscopy reveals global blue-greyish homogeneous pattern with the presence of multiple white rosettes and the absence of dots.

\section{Consent}

The examination of the patient was conducted according to the Declaration of Helsinki principles.

The authors certify that they have obtained all appropriate patient consent forms. In the form the patient(s) has/have given his/her/their consent for his/ her/their images and other clinical information to be 
www.odermatol.com

reported in the journal. The patients understand that their names and initials will not be published and due efforts will be made to conceal their identity, but anonymity cannot be guaranteed.

\section{REFERENCES}

1. Ota M. Nevus fusco-caeruleus ophthalmic-maxillaris. Jap J Dermatol. 1939;46:369.

2. Elmas OF, Kilitçi A. Dermoscopic findings of nevus of Ota. Balkan Med J. Balkan Med J. 2019 Dec 19.
3. Haspeslagh M, Noë M, De Wispelaere I, Degryse N, Vossaert K, Lanssens S, et al. Rosettes and other white shiny structures in polarized dermoscopy: histological correlate and optical explanation. J Eur Acad Dermatol Venereol. 2016;30:311-3.

4. Salas-Callo CI, Riera-Monroig J, Podlipnik S, Puig S. Blue nevus with rosettes on polarized light dermoscopy. Dermatol Pract Concept. Dermatol Pract Concept. 2019;10:e2020017.

Copyright by Selma El Kadiri, et al. This is an open-access article distributed under the terms of the Creative Commons Attribution License, which permits unrestricted use, distribution, and reproduction in any medium, provided the original author and source are credited.

Source of Support: Nil, Conflict of Interest: None declared. 